\title{
Stereospecific Fragmentations \\ in the Mass Spectra of Stereoisomeric \\ Isoindoloquinazolines
}

\author{
Vladimir V. Ovcharenko and Kalevi Pihlaja \\ Structural Chemistry Group, Department of Chemistry, University of Turku, Turku, Finland \\ Géza Stájer \\ Institute of Pharmaceutical Chemistry, University of Szeged, Szeged, Hungary
}

The mass spectrometric behavior of stereo- and regioisomeric, partially saturated isoindoloquinazolines was studied by positive-ion electron ionization (EI) and fast-atom bombardment (FAB/LSIMS) mass spectrometry combined with collision-induced dissociation (CID). A highly stereospecific retro-Diels-Alder process was observed in the cyclohexene-fused isomers under the EI conditions, and a corresponding (although less specific) fragmentation was observed in their FAB spectra. In the absence of RDA fragmentations, regio- and stereoisomers of the cyclohexane-fused heterocycles could be distinguished based on their FAB/CID spectra. (J Am Soc Mass Spectrom 2003, 14, 1049-1056) (c) 2003 American Society for Mass Spectrometry

$\mathrm{V}$ arious condensed-skeleton heterocycles containing up to three rings can be prepared starting from stereoisomeric aminobicycloalkanecarboxylic acids by applying a retro-Diels-Alder (RDA) decomposition as a part of the synthetic strategy. For instance, the reaction of 3-aminobicyclo[2.2.1]hept-5ene-2-carboxylic acid with formylbenzoic acid followed by a mild thermolysis of the pentacyclic intermediate afforded the novel 1,3-oxazino[2,3-a]indole-2,6-dione [1]. In this case, the norbornene moiety, which is subsequently split off as cyclopentadiene, serves as a vehicle for introducing heteroatoms in the target structure. Sometimes the thermolytic step is accompanied by side reactions, such as the methyl group migration observed in norbornene-fused 1,3-thiazino[3,2-a]pyrimidinones [2], which may limit the applicability of this synthetic strategy.

Recently, isomeric heterocycles 1-6 (Scheme 1) were prepared by the reactions of 2-formylbenzoic acid with cis- and trans-aminocyclohex(ane/ene)methylamines, and their structures and stereochemistry were established by NMR methods [3]. Starting from cis-aminocyclohexanemethylamine, three isomers (3-5) were isolated from the reaction mixture, while both the trans derivatives and cis-cyclohexenyl compounds each resulted in one product only. The mass-spectrometric

Published online July 28, 2003

Address reprint requests to Dr. K. Pihlaja, Structural Chemistry Group, Department of Chemistry, University of Turku, FIN-20014 Turku, Finland. E-mail: kpihlaja@utu.fi behavior of these compounds under the EI and FAB conditions is reported in the present study.

The choice of experimental methods was dictated by the following considerations. Mass-spectrometric RDA fragmentations often proceed in a regio- or stereospecific manner $[4,5]$. The structure-specificity of RDA phenomena have previously been studied by us in the mass spectra of stereoisomeric polycondensed heterocycles using various ionization methods, such as electron impact (EI) [6], chemical (CI) [7], and electrospray (ESI) ionization [8]. The use of different ionization methods in studying structure-specific RDA fragmentations is beneficial for two reasons. First, it is always important to distinguish between the purely massspectrometric RDA decomposition of gas-phase ionic species and the corresponding, thermally induced process. Secondly, variation of the ionization and fragmentation conditions (e.g., EI versus "soft" ionization; or spontaneous versus collision-induced fragmentation) may alter the relative significance of the available channels for fragmentation. A recent study of the RDA fragmentations in partially saturated $4 H$-chromenes illustrates both these points [9]. Two different RDA fragmentations were observed in the EI and CI mass spectra of these heterocycles (Scheme 2). Under the CI conditions, only one of these RDA processes (involving the decomposition of the pyran ring) occurred from either $\mathrm{MH}^{+}$or $[\mathrm{M}-\mathrm{H}]^{-}$ions, but both RDA types were observed under the EI conditions, although in this case they only occurred as secondary fragmentations (not directly from $\mathrm{M}^{+} \bullet$ ). Moreover, the relative abundances of the fragment ions corresponding to the RDA-2 type 
SCHEMES<smiles>O=C(c1ccccc1)N1[CH]N[C@H]2CC=CC[C@H]2C1</smiles><smiles>[2H][C@]12CC=CC[C@H]1N[C@@]1(C)c3ccccc3C(=O)N1C2</smiles><smiles>C[C@@]12CN(C(=O)c3ccccc31)[C@H]1CCCC[C@H]1N2</smiles><smiles>C[C@]12CCCC[C]1CN1C(=O)c3ccccc3[C@H]1N2</smiles><smiles>O=C1c2ccccc2[C@H]2N[C@@H]3CCCC[C]3CN12</smiles><smiles>C[C@H]1NC[C@@H]2CCCC[C@@]21C</smiles>

Scheme 1. Partially saturated isoindoloquinazolines (cyclohexene- and cyclohexane-fused pyrimido[2,1-a]isoindol-6-ones) 1-6.

(Scheme 2) of the EI-induced fragmentation increased from $0-25$ to $70-100 \%$ RA when raising the ion source temperature from 200 to $350{ }^{\circ} \mathrm{C}$ [9].

"Soft" ionization methods, such as ESI, usually do not produce abundant fragment ions. However, subjecting ESI-generated ions to collision-induced dissociation (CID) is a powerful method of studying various structural effects. Thus, tandem mass spectrometry (CID/ argon, 30-90 eV collision energy) of $[\mathrm{M}-\mathrm{H}]^{-}$ions produced by ESI from isomeric flavonoids revealed a number of regiospecific RDA fragmentations [10]. The abundance of RDA fragment peaks strongly depended on the position of hydroxyl groups (e.g., 4'-hydroxy versus 6-hydroxyflavone, because the position of the hydroxyl group determines the localization of negative charge in $[\mathrm{M}-\mathrm{H}]^{-}$ions), but it also varied between flavones (e.g., apigenin) and isoflavones (e.g., daidzein and genistein).

Fast-atom bombardment (FAB, or LSIMS) may be even more advantageous for studying regio- and stereospecific RDA fragmentations, because samples are ionized at ambient temperatures precluding thermal RDA decompositions (whereas the use of CI involves sample evaporation into a heated ion source prior to ionization), and there are typically more abundant fragment ions in the FAB spectra (compared to ESI spectra) even without collision activation. Still, most of

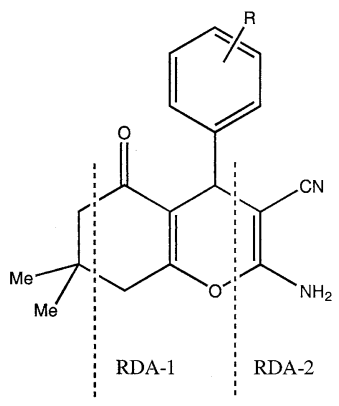

\begin{tabular}{|l|l|l|l|}
\hline $\begin{array}{l}\text { Ionization } \\
\text { method }\end{array}$ & Parent ion & RDA-1 & RDA-2 \\
\hline \multirow{3}{*}{$\mathrm{EI}^{+}$} & $\mathrm{M}^{+\bullet}$ & - & - \\
\cline { 2 - 4 } & {$\left[\mathrm{M}-\mathrm{C}_{6} \mathrm{H}_{4} \mathrm{R}\right]^{+}$} & $\mathrm{x}$ & - \\
\cline { 2 - 5 } & {$\left[\mathrm{M}-\mathrm{R}^{+}\right.$} & - & $x$ \\
\hline \multirow{2}{*}{$\mathrm{CI}^{+}$} & {$[\mathrm{M}+\mathrm{H}]^{+}$} & - & $x$ \\
\cline { 2 - 4 } $\mathrm{CI}$ & {$[\mathrm{M}-\mathrm{H}]^{-}$} & - & $x$ \\
\hline
\end{tabular}

Scheme 2. Regiospecific RDA fragmentations in partially saturated $4 H$-chromenes depending on the ionization conditions [9].

the studies reported in the literature used collision activation of FAB-generated ions [11-13]. Under these conditions, RDA fragmentations were observed in flavonoids [11, 12], flavonoid-O-glycosides [12], and phenanthroindolizidine alkaloids [13]. Variation of experimental conditions can enhance the structure-specific fragmentations in FAB-generated ions. Thus, differentiation of the regioisomers and anomers of some C-aryl glycosides was made possible by analyzing the MIKE spectra of their $[\mathrm{M}+\mathrm{Li}]^{+}$or $[\mathrm{M}+\mathrm{Na}]^{+}$ions, but not of the $[\mathrm{M}+\mathrm{H}]^{+}$ions [14].

\section{Experimental}

The mass spectra were recorded on a VG ZABSpecoaTOF mass spectrometer (VG Analytical, Manchester, UK) equiped with OPUS data acquisition software. In the EI mode, samples were introduced using watercooled direct insertion probe at ambient temperatures. The ionization energy of $70 \mathrm{eV}$ and trap current of 200 $\mu \mathrm{A}$ were used for producing positive ions. Basic spectra were obtained at a resolving power of 1000. Accurate mass measurements were performed at a resolving power of $8000-10,000$ using peak matching and PFK as the reference compound. Metastable ions spectra $(B / E$ and $\mathrm{B}^{2} / \mathrm{E}$ linked scans) were obtained at a precursor ion resolving power of 5000. The elemental compositions and routes of formation of the fragment ions discussed in the text were confirmed by accurate mass measurements and metastable ion spectra.

The FAB spectra were produced by LSIMS ionization 
Table 1. The 70-eV EI mass spectra of cyclohexene-fused pyrimido[2,1-a]isoindol-6-ones 1,2. Only ions with the relative abundance values of $\geq 3 \%$ RA are listed

\begin{tabular}{|c|c|c|c|c|c|c|}
\hline$m / z$ & 1 (cis-fused) & 2 (trans-fused) & $\begin{array}{c}\text { lon compositions } \\
\text { (confirmed by HRMS) }\end{array}$ & Calcd. & $\begin{array}{c}\text { Obsd. } \\
\text { (data for 1) }\end{array}$ & $\Delta, \mathrm{mDa}$ \\
\hline 241 & 5 & 4 & & & & \\
\hline 240 & 26 & 32 & $\mathrm{M}^{+\cdot}$ & & & \\
\hline 239 & 18 & 100 & {$[\mathrm{M}-\mathrm{H}]^{+}$} & & & \\
\hline 186 & 100 & 17 & {$\left[\mathrm{M}-\mathrm{C}_{4} \mathrm{H}_{6}\right]^{+\cdot}(\mathrm{RDA})$} & 186.0793 & 186.0794 & 0.1 \\
\hline 159 & 9 & 4 & $\begin{array}{l}{\left[\mathrm{M}-\mathrm{C}_{5} \mathrm{H}_{7} \mathrm{~N}\right]^{+\cdot a}} \\
{\left[\mathrm{M}-\mathrm{C}_{6} \mathrm{H}_{9}\right]^{+}}\end{array}$ & $\begin{array}{l}159.0684 \\
159.0558\end{array}$ & $\begin{array}{l}159.0690 \\
159.0562\end{array}$ & $\begin{array}{l}0.6 \\
0.4\end{array}$ \\
\hline 147 & 4 & 5 & {$\left[\mathrm{M}-\mathrm{C}_{7} \mathrm{H}_{9}\right]^{+}$} & & & \\
\hline 145 & 5 & 3 & {$\left[\mathrm{M}-\mathrm{C}_{6} \mathrm{H}_{9} \mathrm{~N}\right]^{+\cdot}$} & & & \\
\hline 132 & 9 & 7 & {$\left[\mathrm{M}-\mathrm{C}_{7} \mathrm{H}_{10} \mathrm{~N}\right]^{+\cdot}$} & & & \\
\hline \multirow[t]{2}{*}{130} & 11 & 7 & $\mathrm{C}_{8} \mathrm{H}_{4} \mathrm{NO}^{+\mathrm{b}}$ & 130.0293 & 130.0292 & 0.1 \\
\hline & & & $\mathrm{C}_{9} \mathrm{H}_{8} \mathrm{~N}^{+b}$ & 130.0657 & 130.0656 & 0.1 \\
\hline \multirow[t]{2}{*}{104} & 5 & 3 & $\mathrm{C}_{7} \mathrm{H}_{6} \mathrm{~N}^{+\mathrm{a}}$ & 104.0500 & 104.0498 & 0.2 \\
\hline & & & $\mathrm{C}_{7} \mathrm{H}_{4} \mathrm{O}^{+\cdot}$ & 104.0262 & 104.0264 & 0.2 \\
\hline 90 & 4 & 3 & & & & \\
\hline 79 & 3 & 3 & & & & \\
\hline 77 & 8 & 6 & & & & \\
\hline 41 & 3 & 3 & & & & \\
\hline
\end{tabular}

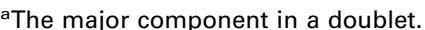

${ }^{\mathrm{b}}$ Components of roughly equal abundance.

$\left(\mathrm{Cs}^{+}\right.$ions bombardment) using 3-nitrobenzyl alcohol (NBA) as liquid matrix. Solid samples were dissolved in $\mathrm{MeOH}$. The spectra were recorded in the positive-ion mode. For CID experiments, helium was used as a collision gas in the first field-free region (1FFR) at a pressure corresponding to $50 \%$ attenuation of the precursor ion signal.

\section{Results and Discussion}

Compounds 1-6 provide several possibilities to study the regio- and stereospecificity of the mass spectrometric fragmentations in partially saturated heterocycles. First, our previous experience [6-8] suggested that the pair of cis- and trans-fused isomers 1,2 would exhibit more or less stereospecific RDA fragmentation under the EI (or CI [7]) conditions. Another interesting question was whether these compounds undergo RDA fragmentations under "softer" ionization conditions at an ambient temperature (e.g., FAB) and if they do, what might be the degree of RDA stereospecificity. On the other hand, the cyclohexane-fused isomers 3-6 were expected to produce EI mass spectra that would be very similar to each other. Here again, the use of a "soft" ionization process producing ions with lower excess internal energies might better set off the subtle differences existing between stereoisomeric structures. Therefore, we studied these compounds under both the EI and FAB conditions, with the emphasis on the CID spectra of their $\mathrm{M}^{+}$and $\mathrm{MH}^{+}$ions.

Table 2. The 70-eV EI mass spectra of cyclohexene-fused pyrimido[2,1-a]isoindol-6-ones 3-6. Only ions with the relative abundance values of $\geq 5 \%$ RA in at least one of the isomers are listed

\begin{tabular}{|c|c|c|c|c|c|}
\hline$m / z$ & $\begin{array}{l}\text { cis-fused, } \\
\text { linear } 3\end{array}$ & $\begin{array}{l}\text { cis-fused, } \\
\text { linear } 4\end{array}$ & $\begin{array}{l}\text { cis-fused, } \\
\text { angular } \mathbf{5}\end{array}$ & $\begin{array}{l}\text { trans-fused } \\
\quad \text { linear } 6\end{array}$ & $\begin{array}{c}\text { Ion compositions (confirmed } \\
\text { by HRMS) }\end{array}$ \\
\hline 243 & 4 & 5 & 4 & 3 & \\
\hline 242 & 34 & 35 & 29 & 27 & $\mathrm{M}^{+\cdot}$ \\
\hline 241 & 100 & 100 & 100 & 100 & {$[\mathrm{M}-\mathrm{H}]^{+}$} \\
\hline 213 & 3 & 4 & 8 & 2 & {$\left[\mathrm{M}-\mathrm{C}_{2} \mathrm{H}_{5}\right]^{+}+[\mathrm{M}-\mathrm{CHO}]^{+\mathrm{a}}$} \\
\hline 199 & 5 & 6 & 2 & 2 & {$\left[\mathrm{M}-\mathrm{C}_{3} \mathrm{H}_{7}\right]^{+}$} \\
\hline 159 & 4 & 5 & 2 & 3 & {$\left[\mathrm{M}-\mathrm{C}_{6} \mathrm{H}_{11}\right]^{+}$} \\
\hline 147 & 7 & 12 & 2 & 8 & {$\left[\mathrm{M}-\mathrm{C}_{7} \mathrm{H}_{11}\right]^{+}$} \\
\hline 133 & 2 & 2 & 10 & 2 & $\mathrm{C}_{8} \mathrm{H}_{7} \mathrm{NO}^{+\cdot}$ \\
\hline 132 & 8 & 9 & 20 & 9 & $\mathrm{C}_{8} \mathrm{H}_{6} \mathrm{NO}^{+}$ \\
\hline 130 & 6 & 8 & 7 & 7 & $\mathrm{C}_{8} \mathrm{H}_{4} \mathrm{NO}^{+}$ \\
\hline 104 & 4 & 4 & 4 & 5 & \\
\hline 77 & 3 & 4 & 5 & 5 & \\
\hline 41 & 4 & 4 & 4 & 7 & \\
\hline
\end{tabular}

${ }^{\mathrm{a} C o m p o n e n t s ~ o f ~ r o u g h l y ~ e q u a l ~ a b u n d a n c e . ~}$ 


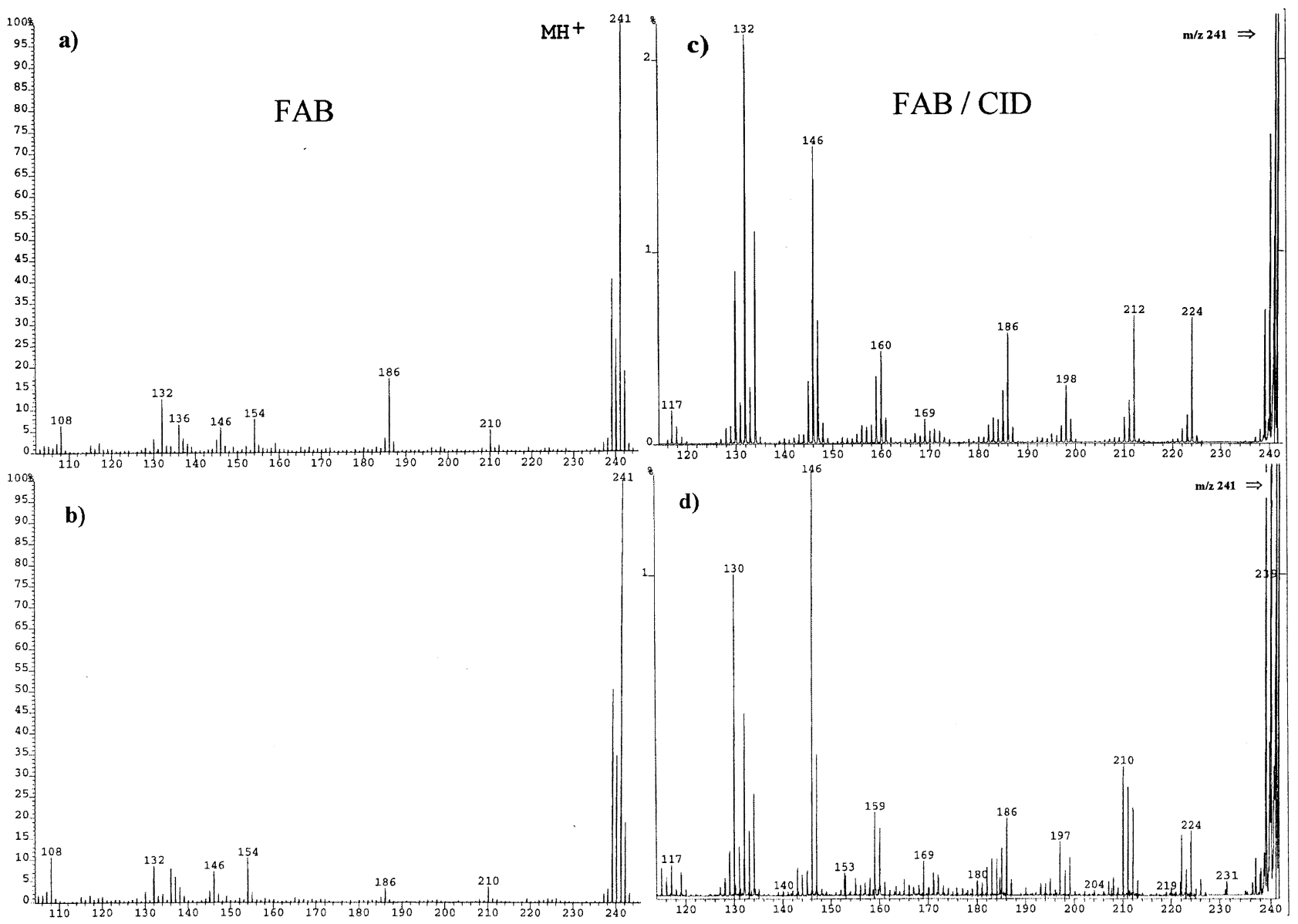

Figure 1. The positive-ion FAB spectra $(\mathbf{a}, \mathbf{b})$ and $\mathrm{FAB} / \mathrm{CID}$ spectra of the $\mathrm{MH}^{+}$ions $(\mathbf{c}, \mathbf{d})$ of the cisand trans-fused heterocycles $\mathbf{1}$ and $\mathbf{2}(\mathbf{a}, \mathbf{c}$ and $\mathbf{b}, \mathbf{d}$, respectively). The relative abundances of peaks at $\mathrm{m} / \mathrm{z} 186$ illustrate the stereospecificity of the corresponding RDA-like fragmentation. Peaks at $\mathrm{m} / \mathrm{z} 154$ and 136-138 $(a, b)$ are from the matrix (3-NBA).

\section{EI Mass Spectra}

The $70 \mathrm{eV}$ positive-ion EI mass spectra of Compounds 1,2, and 3-6 are listed in Tables 1 and 2, respectively. All these compounds are characterized by stable $\mathrm{M}^{+}{ }^{\bullet}$ ions (ca. 30\% RA), and the base peaks correspond to [M $\mathrm{H}]^{+}$ions (30-40\% of the total ion current, TIC) in all cases but one. The relative abundances of $\left[\mathrm{M}-\mathrm{C}_{4} \mathrm{H}_{6}\right]^{+}$ peaks at $\mathrm{m} / \mathrm{z} 186$ in the spectra of $\mathbf{1}$ and $\mathbf{2}$ indicate a highly stereospecific RDA fragmentation. The [M $\left.\mathrm{C}_{4} \mathrm{H}_{6}\right]^{+} \cdot$ ions were shown (by the metastable ion spectra) to originate directly from the $\mathrm{M}^{+} \cdot$. There are no other significant channels of fragmentation in the spectra of $\mathbf{1}$ and $\mathbf{2}$ that would differentiate these two stereoisomers. The difference in carbocycle saturation (cyclohexene- versus cyclohexane-fused Compounds 1-6) is manifested (apart from the RDA fragmentations) by the greater propensity of the saturated derivatives 3-6 to form $\left[\mathrm{M}-\mathrm{C}_{\mathrm{x}} \mathrm{H}_{\mathrm{y}}\right]$ ions via the loss of hydrocarbon fragments. The angularly annelated isomer 5 differs from the rest of these saturated derivatives by the greater relative abundance of the $\mathrm{C}_{8} \mathrm{H}_{7} \mathrm{NO}^{+}{ }^{\cdot}$ and $\mathrm{C}_{8} \mathrm{H}_{6} \mathrm{NO}^{+}$ions (Table 2), but no significant differences could be detected between the cis- and trans-fused stereoisomers of the linearly annelated, cyclohexanefused compounds. The metastable ion spectra obtained from the $\mathrm{M}^{+}{ }^{\bullet}$ ions of 3-6 with or without collisional activation are also very similar to each other. They are dominated by peaks of $\left[\mathrm{M}-\mathrm{C}_{6} \mathrm{H}_{11}\right]^{+}$and $[\mathrm{M}-$ $\left.\mathrm{C}_{7} \mathrm{H}_{11}\right]^{+}$ions with approximately the same abundance ratios. The angularly annelated isomer 5 again differs from the other compounds, but only quantitatively: Thus, its metastable $\mathrm{M}^{+}$ions decompose to produce more abundant $\mathrm{C}_{7} \mathrm{H}_{11}^{+}$ions than those originating from the linearly annelated isomers. This type of difference is understandable because the complementary [M $\left.\mathrm{C}_{7} \mathrm{H}_{11}\right]^{+}$and $\mathrm{C}_{7} \mathrm{H}_{11}^{+}$ions are formed by the cleavage of the cyclohexane ring, and it is by its annelation geometry that the parent molecules actually differ from each other.

Thus, the only stereospecific fragmentation process observed in the EI mass spectra of Compounds 1-6 is the RDA decomposition in the case of the cyclohexene-fused derivatives. That the rate of the RDA decomposition is higher in the cis-fused isomers is 

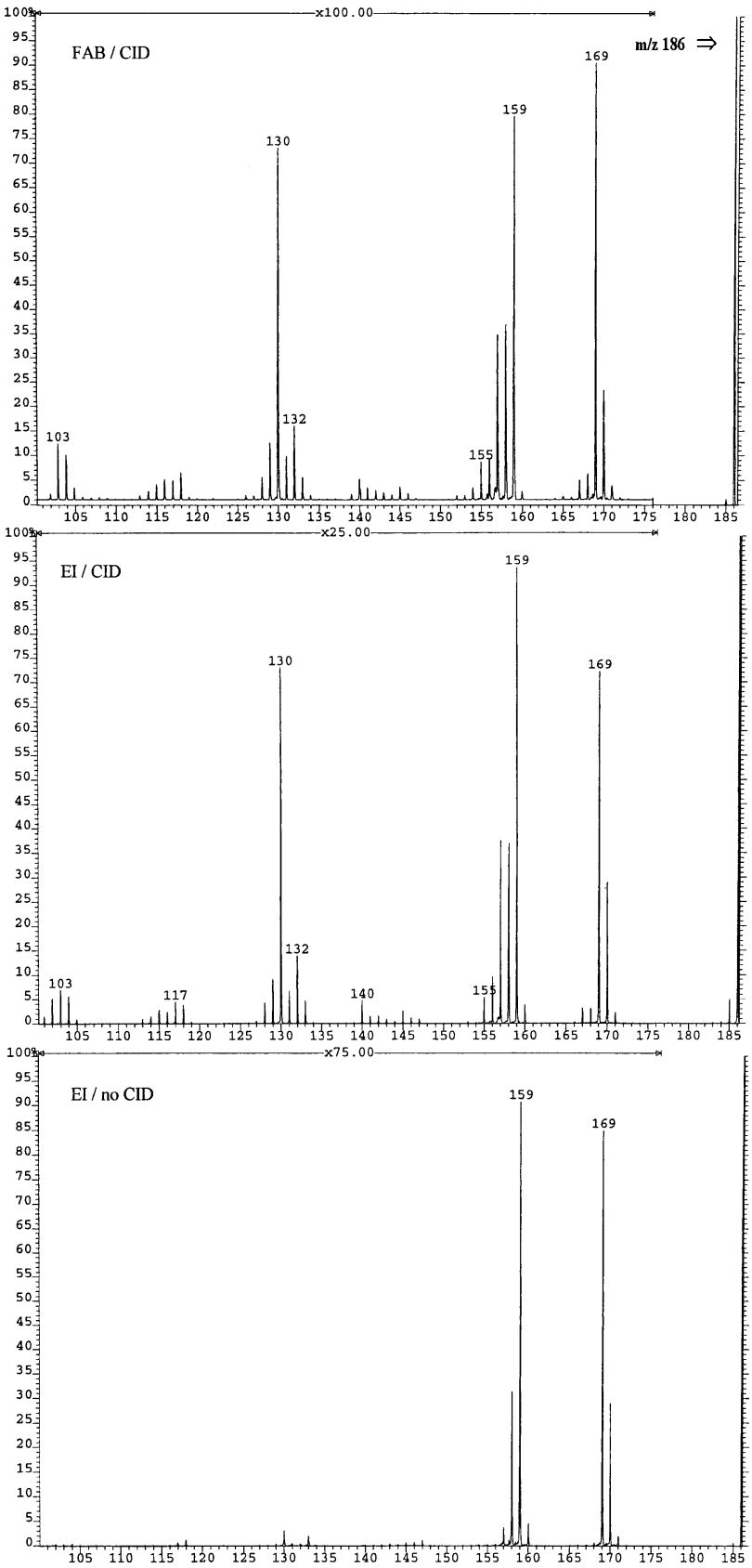

Figure 2. Product ion spectra obtained in the 1 FFR from ions $\mathrm{m} / \mathrm{z}$ 186 generated from Compound $\mathbf{1}$ under FAB or EI conditions with or without collisional activation. The CID (He) spectra (the top and middle boxes) suggest a common structure for the $\mathrm{m} / \mathrm{z} 186$ ions produced by different ionization methods.

consistent with the previous research [4, 6]. The linearly and angularly annelated isomers, but not the cis/trans cyclohexane-fused isomers could also be differentiated on the basis of their EI mass spectra. In other words, the EI-induced fragmentation of the saturated Compounds 3-6 is regiospecific, but not stereospecific.

\section{FAB Mass Spectra}

The positive-ion FAB mass spectra of the cyclohexene derivatives 1,2 are shown in Figure 1 (the left column). Apart from the expected peaks of $\mathrm{MH}^{+}$ions at $\mathrm{m} / \mathrm{z} 241$, there are also abundant peaks of $\mathrm{M}^{+}$and $[\mathrm{M}-\mathrm{H}]^{+}$ (same as $[\mathrm{MH}-2 \mathrm{H}]^{+}$) ions demonstrating that, similarly to the EI conditions, these compounds easily undergo hydride abstraction. Note also abundant peaks of ions with $\mathrm{m} / \mathrm{z} 240$ in the FAB/CID spectra of both 1 and 2 (Figure 1c, d). A prominent fragment peak was found at $m / z 186$, which can possibly correspond to the loss of ${ }^{\bullet} \mathrm{C}_{4} \mathrm{H}_{7}$ radicals from the $\mathrm{MH}^{+}$or else to the loss of $\mathrm{C}_{4} \mathrm{H}_{6}$ from $\mathrm{M}^{+} \cdot$. However, the presence of $m / z 186$ peaks in the CID spectra of $\mathrm{MH}^{+}$ions $(\mathrm{m} / \mathrm{z} 241$, Figure 1c, d) confirms that at least some part of these ions originates under the FAB conditions directly from the $\mathrm{MH}^{+}$by a mechanism which must be different from the EI-induced fragmentation starting from $\mathrm{M}^{+} \cdot$. The FABgenerated $\left[\mathrm{MH}-\mathrm{C}_{4} \mathrm{H}_{7}\right]^{+\bullet}$ ions seem to have the same structure as their $\left[\mathrm{M}-\mathrm{C}_{4} \mathrm{H}_{6}\right]^{+}$counterparts formed under the EI conditions, as can be seen from the respective product ion spectra (Figure 2 and Scheme 3). Losses of radical species leading to odd-electron cations, which apparently violate the even-electron rule, are not common under the $\mathrm{FAB}$ conditions, but so is the formation of abundant $\mathrm{M}^{+}$ions as well (Figure 1). Note that hydride abstraction leading to $[\mathrm{M}-\mathrm{H}]^{+}$ions is also conspicuous in the EI mass spectra of Compounds 1-6.

The loss of ${ }^{\cdot} \mathrm{C}_{4} \mathrm{H}_{7}$ from the FAB-generated $\mathrm{MH}^{+}$ ions of $\mathbf{1}$ and $\mathbf{2}$ is not likely to occur as a concerted electrocyclic reaction. Therefore, it is not expected to be as highly stereospecific as a concerted RDA fragmentation (see, e.g., reference [4] for a discussion). Still, it is seen from Figure 1 that the RDA peaks are higher in the spectra of the cis-fused isomer 1 . This may be interpreted as an evidence that the $\mathrm{m} / \mathrm{z} 186$ ions are at least partly formed in a two-step sequence via the $\mathrm{M}^{+}$ions generated by hydride abstraction from the $\mathrm{MH}^{+}$.

The FAB spectra of the cyclohexane-fused Compounds 3-6 show very little fragmentation. However, the CID spectra of their $\mathrm{MH}^{+}$ions show abundant fragments in the range of $\mathrm{m} / \mathrm{z} 130-160$, and their relative abundances clearly differ between the isomers (Figure 3). Although the two linearly annelated cis-fused isomers 3 and 4 (Figure $3 a, b$ ) produce very similar CID spectra, they can be easily distinguished from the angularly annelated (Figure 3c) and transfused (Figure 3d) isomers by the abundances of peaks at around $\mathrm{m} / \mathrm{z} 146$ and 160 . Assuming that the fragment ion compositions correspond to those formed under the EI conditions, these diagnostic ions have the general formulas [ $\left.\mathrm{MH}-\mathrm{C}_{x} \mathrm{H}_{y}\right]$, where $x=6-7$, and are produced by the splitting off of the cyclohexane moiety fused to the heterocycle. The $a$ and $b$ fragmentation routes shown in Scheme 3 correspond to the losses of $C_{7}$ and $C_{6}$ fragments, respectively. 
cyclohexene-fused 1, 2

<smiles>O=C1c2ccccc2C2NC3CC=CCC3CN12</smiles>

$\mathrm{M}^{+\cdot}(\mathrm{El})$ $\mathrm{MH}^{+} \quad(\mathrm{FAB})$<smiles>CCCCCCC</smiles>

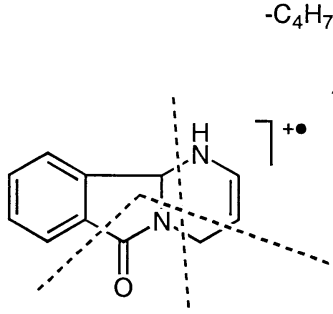

$m / z 186$



159

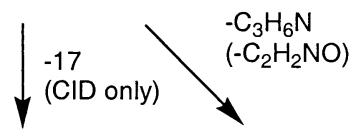

169
$130(\mathrm{CID}, \mathrm{EI})$

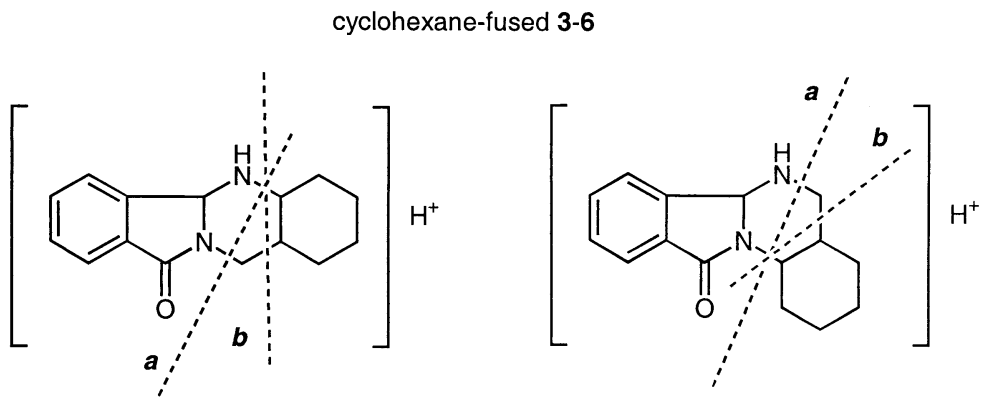

Scheme 3. Specific fragmentation routes observed in Compounds 1-6 under various ionization conditions.

That the CID spectrum of 5 shows the most abundant $\left[\mathrm{MH}-\mathrm{C}_{6} \mathrm{H}_{11}\right](\mathrm{m} / \mathrm{z} 160)$ peak among all the isomers 3-6 is especially noteworthy because the angular isomer is the only one where there is no methylene group attached to the bridgehead nitrogen of the pyrimidine ring. Fragmentation of 5 by route $\boldsymbol{b}$ would involve a classical $\beta$-cleavage with respect to the amine nitrogen atom. No clear trends could be observed in the relative abundances of $\mathrm{m} / \mathrm{z} 146-147$ regarding route $\boldsymbol{a}$ (Figure 3). Note, however, that the relative abundance of the $\mathrm{m} / \mathrm{z} 147$ peak in the EI spectrum of 5 (Table 2) is minimal compared to the other cyclohexane-fused isomers.

Thus, both regio- and stereospecific fragmentations were observed in the CID spectra of the FAB-generated $\mathrm{MH}^{+}$ions of Compounds 3-6, and they are directly related to the structural differences between these isomers.

\section{Conclusions}

The present study has demonstrated the persistence and conservation of the stereospecificity of mass spec- 

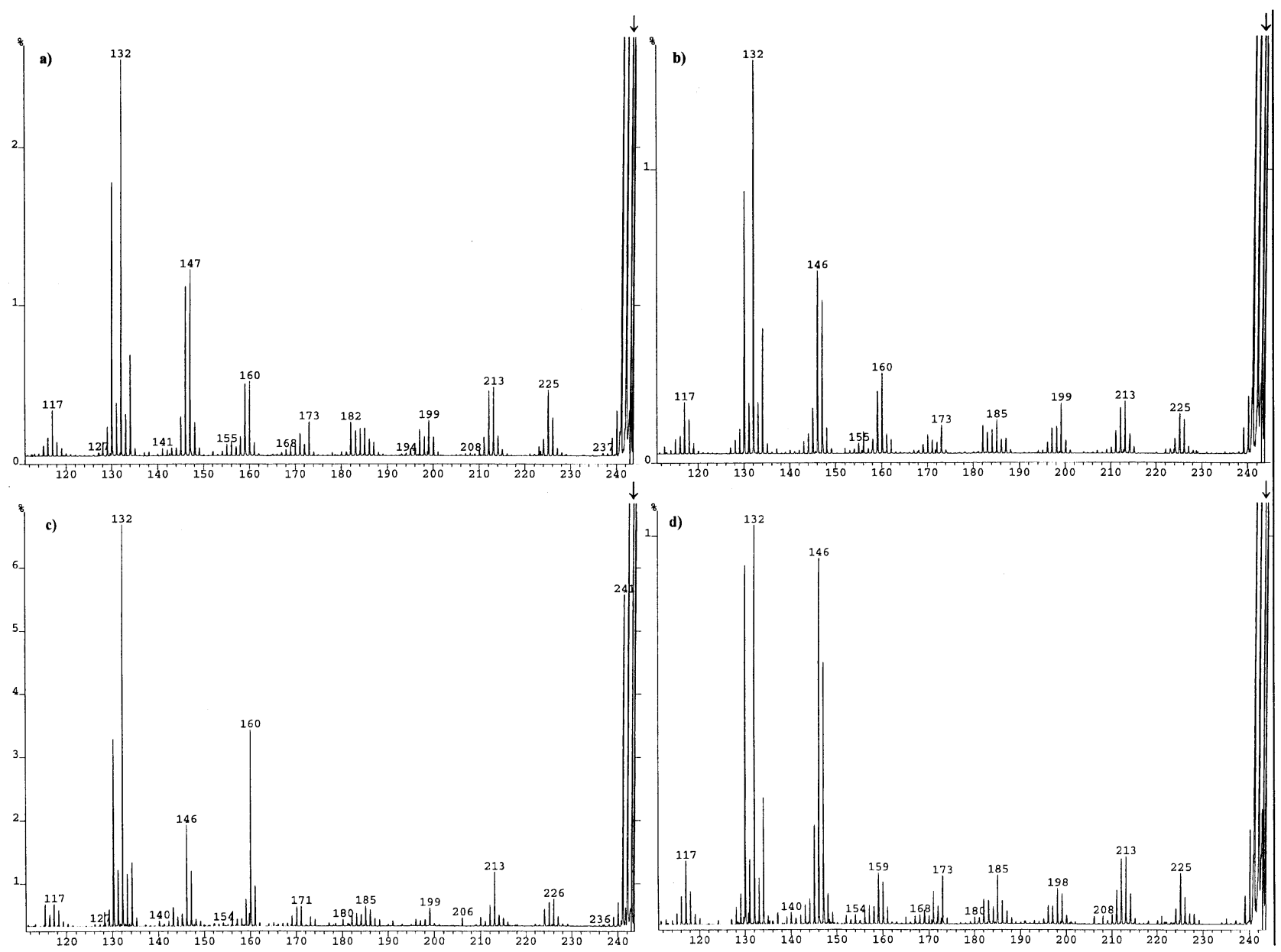

Figure 3. The CID spectra of the $\mathrm{MH}^{+}$ions $(\mathrm{m} / \mathrm{z} 243)$ produced by FAB ionization from the isomeric heterocycles 3-6 (a-d, respectively). The cis- and trans-fused (a, b versus $\mathbf{d})$, as well as linear and angular isomers (b versus c) clearly differ by the relative abundances of peaks in the $\mathrm{m} / \mathrm{z} 130-160$ range.

trometric fragmentations (such as RDA and similar processes) observed in the cis- and trans-cyclohexenefused heterocycles under various ionization conditions (EI and FAB). The regio- and stereoisomers of cyclohexane-fused heterocycles could be differentiated on the basis of the CID spectra of their FAB-generated $\mathrm{MH}^{+}$ ions.

\section{References}

1. Stájer, G.; Szabó, A. E.; Sohár, P.; Szúnyog, J.; Bernáth, G. The First Preparation of a Heterotricycle, [1,3] Oxazino[2,3-a]Isoindole-2,6-Dione, by a Retro-Diels-Alder Method. Synthesis 1998, $718-720$.

2. Stájer, G.; Szabó, A.E.; Sohár, P. Synthesis and Structure of Norbornane/Ene-Fused Thiouracils and Thiazino[3,2-a]Pyrimidinones. Heterocycles 1999, 51, 1849-1854.

3. Sohár, P.; Stájer, G.; Szabó, A. E.; Szúnyog, J.; Bernáth, G. Saturated Heterocycles. Part 257. Preparation and Structure of Partially Saturated Isoindolo[1,2-b]- and -[2,1-a]Quinazolinones. Heterocycles 1998, 48, 175-180.

4. Mandelbaum, A. Stereochemical Effects in the Retro-DielsAlder Fragmentation. In Applications of Mass Spectrometry to
Organic Stereochemistry; Splitter, J. S.; Turecek, F., Eds.; VCH: New York, 1994; 299-324.

5. Morlender-Vais, N.; Mandelbaum, A. Stereospecific RetroDiels-Alder Fragmentation of Stereoisomeric 3-Methoxy- and 3,6-Dialkoxytricyclo[6.2.2.0 2,7] Dodeca-9-Enes Upon Electron Ionization. J. Mass Spectrom. 1998, 33, 229-241.

6. Pihlaja, K.; Ovcharenko, V.; Stájer, G. Stereospecific Fragmentation Processes in Cycloalkane/Cycloalkene-Fused Isomers of Saturated Pyrrolo[2,1-b][1,3]oxazin-6-Ene Derivatives. J. Am. Soc. Mass Spectrom. 1999, 10, 393-401.

7. Ovcharenko, V.; Shaikhutdinov, R. A.; Pihlaja, K.; Stájer, G. Mass-Spectrometric Differentiation of Diexo- and DiendoFused Isomers of Norbornane/Ene-Condensed 2-Thiouracil and 1,3-Thiazino[3,2-a]Pyrimidine Derivatives: Stereoselectivity of Retro-Diels-Alder Fragmentations Under EI and CI Conditions. J. Am. Soc. Mass Spectrom. 2001, 12, 1011-1019.

8. Lemaire, D.; Serani, L.; Laprévote, O.; Ovcharenko, V.; Pihlaja, K.; Stájer, G. Energy-Resolved Electrospray Mass Spectrometry of Diexo-Norbornane and Norbornene Derivatives Containing a Fused, Phenyl-Substituted, 1,3-Oxazine Ring: Competitive Retro-Diels-Alder Fragmentation Processes. Eur. Mass Spectrom. 1999, 5, 253-257.

9. Martin, N.; Martínez-Alvarez, R.; Seoane, C.; Suárez, M.; Salfran, E.; Verdecia, Y. Kayali; Sayadi, N. An Overview of the 
Retro-Diels-Alder Reaction in Semiunsaturated Heterocyclic Rings: Mass Spectra of New Substituted 1,4,5,6,7,8-Hexahydroquinolines and Their Oxo-Analogues 5,6,7,8-Tetrahydro4H-Chromenes. Rapid Commun. Mass Spectrom. 2001, 15, 2024.

10. Hughes, R. J.; Croley, T. R.; Metcalfe, C. D; March, R. E. A. Tandem Mass Spectrometric Study of Selected Characteristic Flavonoids. Int. J. Mass Spectrom. 2001, 210/211, 371-385.

11. Ma, Y. L.; van den Heuvel, H.; Claeys, M. Characterization of 3-Methoxyflavones Using Fast-Atom Bombardment and Collision-Induced Dissociation Tandem Mass Spectrometry. Rapid Commun. Mass Spectrom. 1999, 13, 1932-1942.
12. Borges, C.; Martinho, P.; Martins, A.; Rauter, A. P.; AlmosterFerreira, M. A. Structural Characterization of Flavonoids and Flavonoid-O-Glycosides Extracted from Genista tenera by FastAtom Bombardment Tandem Mass Spectrometry. Rapid Commun. Mass Spectrom. 2001, 15, 1760-1767.

13. Xiang, Y.; Abliz, Z.; Li, L.; Huang, X.; Yu, S. Study of Structural Characteristic Features of Phenanthriondolizidine Alkaloids by Fast Atom Bombardment with Tandem Mass Spectrometry. Rapid Commun. Mass Spectrom. 2002, 16, 1668-1674.

14. Moineau, C.; Sinou, D.; Becchi, M.; Bobenrieth, M. J. Studies of Unsaturated C-Aryl Glycosides by Fast-Atom Bombardment Mass Spectrometry. Eur. J. Mass Spectrom. 2001, 7, 249-258. 